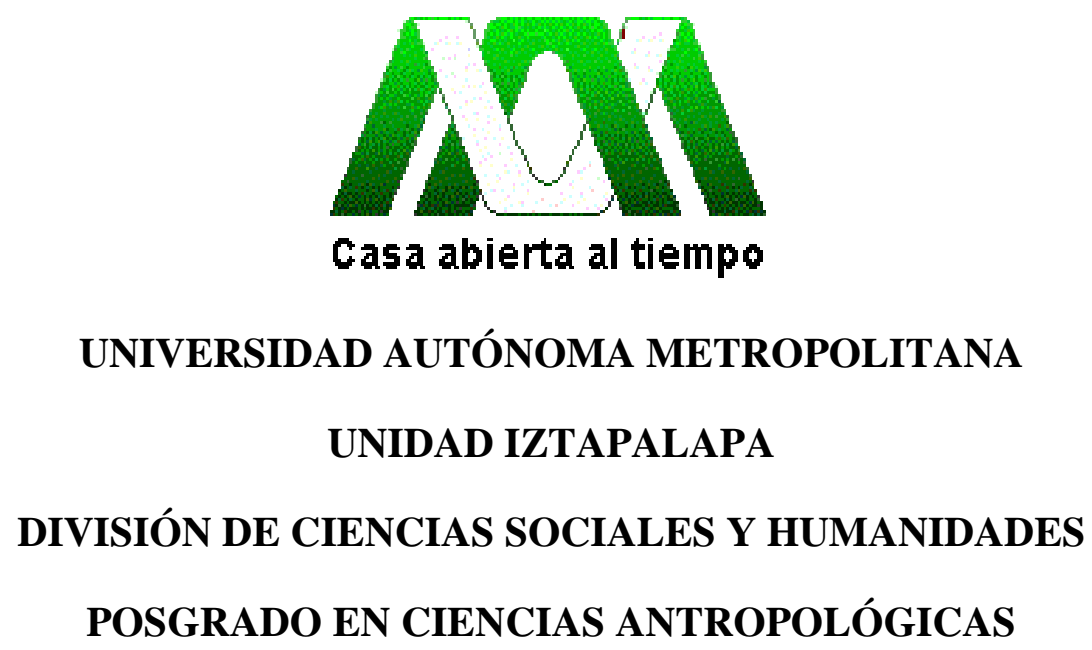

Fotografía del amor y la sexualidad entre jóvenes en el México actual

Gabriela Montoya Gastélum

ENSAYO

Para obtener el Diploma de Especialización

en Antropología de la Cultura

Director: Dr. Néstor García Canclini 


\section{FOTOGRAFÍA DEL AMOR Y LA SEXUALIDAD ENTRE JÓVENES EN EL MÉXICO ACTUAL}

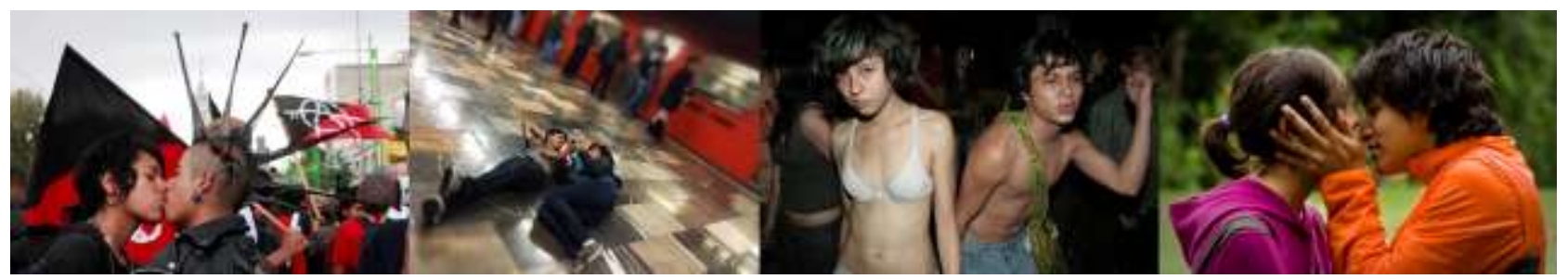

Con su entrada en la adolescencia, la actividad sexual de un muchacho o de una niña, toma un carácter más serio. Deja de ser un simple juego infantil para ocupar un lugar importante entre

los intereses vitales. Lo que antes fuera un comercio inconstante, reducido a un cambio de manipulaciones eróticas, pasa a ser un objeto de serios empeños. Un adolescente se aficiona definitivamente a una persona dada, desea poseerla, trabaja para conseguir este objeto procura obtener la realización de su deseo por medios mágicos y de otro género y logra, finalmente satisfacción completa. Yo he visto jóvenes de esta edad sumidos en la mayor angustia a causa de sus fracasos amorosos. (...) El muchacho tiene un deseo cada vez mayor de poder contar, durante cierto tiempo al menos, con la fidelidad y el cariño exclusivo de la mujer querida. Pero este deseo no está asociado a la idea de establecer relaciones exclusivas, pues los adolescentes no piensan todavía en el matrimonio. Tanto el muchacho como la chica desean gozar todavía de completa libertad y no aceptar obligaciones de por vida.

B. Malinowski

\section{Introducción}

En el texto "The New Anthropology of Sexuality", Andrew P. Lyons y Harriet D. Lyons de manera muy atinada remarcan que si bien la sexualidad ha sido un tema central en la antropología no debe olvidarse que también durante largos periodos de la disciplina la investigación de ésta se dejó en los rincones más lejanos. Tanto en los siglos XVIII, XIX y parte del XX el estudio de la sexualidad fue pieza elemental en la formación de representaciones sobre los "otros primitivos" así como de creación de imágenes de diferencia en sociedades metropolitanas (2006:53).

En la década de los veinte del siglo pasado personajes como Bronislaw Malinowski y Margaret Mead fueron cruciales en el desarrollo de la antropología de la sexualidad demostrando que trobriandeses y samoanos practicaban una sexualidad distinta a la de las sociedades occidentales y que por tanto el ejercicio de ésta tenía que ver con algo más allá de lo natural, es decir, con la cultura. 
El motivo por el cual los primeros antropólogos citados, académicos de la University of Waterloo de Canadá, consideran que la antropología abandonó las pesquisas sobre la sexualidad radica en el hecho de que los antropólogos buscaban el respeto científico prefiriendo dejar de lado por cuarenta años los tópicos que involucraban límites difusos entre naturaleza y cultura.

Por si fuera poco, cuando al estudio de la sexualidad se incluye el estudio del amor exponencialmente hay una tendencia dentro de las ciencias sociales por dejarle las pesquisas específicamente a la psicología en lugar de reconocer que la riqueza de investigar este tema recae en el hecho de que al adentrase en la comprensión del amor se está aprobando la subjetividad en el campo de los estudios culturales. El amor es un vínculo social y por tanto "El análisis de lo amoroso puede proporcionar pistas para comprender el amor, no sólo como estado interno, sino como la relación de la experiencia íntima con las instituciones, la sociabilidad y el poder" (Corona y Rodríguez, 2000:49).

A las nociones de sexualidad y amor quiero agregar un elemento más: los jóvenes. El interés por conocerlos igualmente se dejó por mucho tiempo en el olvido y es hasta años recientes que diferentes investigadores se han preocupado por incluirlos como sujetos de estudio. El saber la manera en que éstos se perciben como tales y cómo van construyendo una identidad juvenil se ha puesto en el centro de las investigaciones. Existe una cantidad considerable de investigadores sociales que estamos interesados en analizar la situación de los jóvenes mexicanos, al igual que Rosario Esteinou nos preguntamos “¿Qué significa ser joven?, especialmente en un país en desarrollo como el nuestro, donde la modernidad y lo tradicional conviven, se mezclan, lo cual se traduce en una variedad de contextos y de perfiles, o de modos de ser joven” (2005:25).

A pesar de este interés, en su obra La construcción juvenil de la realidad. Jóvenes mexicanos contemporáneos, Maritza Urteaga hace una crítica a los trabajos sobre juventud desde la antropología, según la autora "Para nadie es un secreto que el estudio de lo juvenil desde la antropología no ha tenido relevancia sino hasta años muy recientes y que los aportes de esta disciplina en la comprensión de lo juvenil han sido escasos, sino nulos, en el país" (2011a:22).

A la vista de estas líneas puede concluirse que hay un vacío teórico y empírico sobre los jóvenes; este vacío incluye un desconocimiento de las prácticas y los imaginarios amorosos y sexuales de los jóvenes que urge ser atendido. Considero que la antropología, como una ciencia con las bases teóricas y metodológicas necesarias, puede aportar al conocimiento sobre la vida y los deseos de los jóvenes. A través de etnografías enfocadas en el estudio del amor y la 
sexualidad de los jóvenes se puede proporcionar información trascendental acerca de cómo los individuos interactúan con la pareja, los pares, la familia y en la sociedad en general. A su vez, la etnografía no es un manual ni un simple resultado, la etnografía como proceso se basa principalmente en la observación pero puede, o mejor dicho debe, incluir todas las herramientas que le sean adecuadas. La propuesta de utilizar estrategías colaborativas, basadas en la fotografía, va en ese camino.

Es objetivo de este ensayo hacer un recuento de los estudios que han abordado la vida amorosa y sexual de los jóvenes desde la antropología, y algunas otras disciplinas hermanas como la sociología y la comunicación, así como proponer una forma de trabajo que permita a los jóvenes ser ellos quienes construyan, a la par del investigador, los propios saberes sobre su vida sexual y amorosa.

El ensayo se divide en siete partes. En el primer apartado se hace una revisión de las primeras investigaciones realizadas desde la antropología sobre la vida amorosa y sexual de los jóvenes "exóticos" a partir del lente de Malinowski y Mead. La segunda sección da un brinco en tiempo y espacio para hacer un brevísimo inventario acerca de los trabajos que se han realizado a nivel nacional sobre los estudios de la condición juvenil. La tercera parte es obligada para entender la posición de los jóvenes en el país pues se presenta un corto balance de la situación económica, política y social actual. En el cuarto apartado nos adentramos a los estudios que se han realizado principalmente en México sobre los significados, prácticas y representaciones del amor y la sexualidad de las consideradas personas jóvenes, incluidos datos estadísticos. La quinta parte aborda la manera de hacer etnografía en el tiempo de Malinowski y el planteamiento que tiene actualmente la antropología visual para ésta. En la penúltima sección, con base en otros trabajos, se hace la propuesta de producir desde otra perspectiva la manera de realizar etnografías, específicamente a partir de estrategias colaborativas que utilizan la fotografía como una herramienta que mucho nos puede aportar. Por último se presentan algunas reflexiones finales que buscan abrir el interés por estas temáticas aún ausentes en el debate de las ciencias sociales. 


\section{El amor y la sexualidad del “otro" a través del lente antropológico de Malinowski y Mead}

De 1915 a 1916 y de 1917 a 1918 Bronislaw Malinowski realizó un agudo trabajo de campo con los pobladores de las islas Trobriand que derivó en la publicación de diferentes textos, el más sobresaliente de ellos Argonauts of the Western Pacífic (Los argonautas del Pacífico occidental) fue publicado en 1922 y hoy día sigue siendo un referente obligado para el interesado en la antropología. ${ }^{1}$ Para el antropólogo estadounidense George Peter Murdock, Malinowski ha influido abundantemente en la teoría antropológica al igual que Morgan, Tylor y Boas, y lo considera al lado de grandes innovadores de otras disciplinas como Adam Smith, Marx, Summer, Freud y Pavlov:

se le clasifica como uno de los grandes innovadores en la historia de las ciencias del comportamiento humano. No sólo contribuyó prominentemente a la completa reorientación de los intereses y perspectiva que han caracterizado a las pasadas dos décadas en antropología, sino que su trabajo ha dejado también una significante impresión sobre la sociología, el derecho y la lingüística $(1943: 443) .^{2}$

Si bien el autor escribía estas líneas en 1943, la vigencia de ellas no ha caducado. Además de la obra ya mencionada, cinco años después salió impreso el trabajo que tituló Sex and Repression in Savage Society (Sexo y represión en la sociedad primitiva) y en 1929, al mismo tiempo que regresaba como profesor de antropología a la University of London, salía a la luz The Sexual Life of Savages in Northwestern Melanesia (La vida sexual de los salvajes del noroeste de la Melanesia). Este libro es una minuciosa etnografía sobre la vida sexual, amorosa y erótica de los indígenas de las islas del archipiélago de la Melanesia. Es de mi especial interés traerlo a colación pues en los últimos años parece haberse olvidado; la pertinencia de cotejarlo en el presente ensayo podrá observarse permeado en todas las secciones.

\footnotetext{
${ }^{1}$ En éste el antropólogo funcionalista hace un análisis del kula, es decir, del sistema de intercambio comercial de los trobriandeses. "[La descripción del kula que hace Malinowski] demuestra que el cambio de objetos utilitarios, que forma parte del sistema Kula, está enteramente subordinado al intercambio de otros objetos sin ninguna clase de utilidad. Siendo a un tiempo empresa comercial y forma de organización social, provista de un transfondo mítico y un ritual mágico, por no mencionar la gran área geográfica en que se desarrolla" (Frazer; 1922:20-21). La riqueza del libro recae tanto en el estudio de este sistema económico y simbólico como por las líneas dedicadas a explicar el método etnográfico: "Un trabajo etnográfico riguroso exige, sin duda, tratar con la totalidad de los aspectos sociales, culturales y psicológicos de la comunidad, pues hasta tal punto están entrelazados que es imposible de comprender uno de ellos sin tener en consideración todos los demás" (Malinowski, 1922:29).

${ }^{2}$ Traducción propia.
} 
La vida sexual enfoca la atención en responder a los cuestionamientos sobre las costumbres, rituales y pensamientos relacionados con aspectos como el amor, el noviazgo, el matrimonio, el embarazo, la diferencia sexual y la psicología del erotismo de los trobriandeses entre otros, es decir, busca contestar sobre los aspectos de la sexualidad del "primitivo", "el salvaje", "el otro".

Para los primitivos isleños de los mares del Sur, como para nosotros, la sexualidad no es una simple cuestión fisiológica, sino algo que implica amor y conquista amorosa, algo que llega a constituir la base de instituciones tan venerables como el matrimonio y la familia; algo que lleva inspiración al arte y es la fuente de sus magias y encantamientos. La sexualidad domina, en efecto, casi todos los aspectos de la cultura. En su sentido más amplio, que es el que asume en el título de esta obra, es más bien una fuerza sociológica y cultural que una simple relación carnal entre dos individuos (Malinowski, 1929:45).

Sin duda el párrafo anterior resaltan dos cosas: por un lado, la afirmación de que la sexualidad es un constructo sociocultural y por otro la valoración que hace del matrimonio y la familia. Para el autor la sexualidad rebasa la esfera de lo natural para dar cuenta de las relaciones sociales; con su mismo argumento puede entenderse por qué considera como venerables al matrimonio y la familia, Malinowski habla desde su otredad, desde su cultura y su tiempo.

A través de su intenso trabajo de campo, el antropólogo polaco logra adentrarse al conocimiento de las prácticas y pensamientos de los diferentes habitantes de las islas Trobriand. Bajo la idea de que el punto máximo del desarrollo humano es la adultez, el fundador de la antropología funcionalista asegura que la historia de la vida erótica de cualquier pueblo debe iniciarse con el estudio de las relaciones de infantes y jóvenes (1929:55). Los trobriandeses, reporta, designan las diferentes edades en tres fases: infancia, madurez y vejez, cada una a su vez se subdividirá.

La adolescencia en los trobriandeses, según el autor, significa dejar atrás la sexualidad infantil para abrirse paso a relaciones permanentes y serias que anteceden al matrimonio. Cuando un joven o una muchacha trobriandes presenta "madurez sexual y desarrollo mental", lo que se hará visible por los cambios fisiológicos, -esto alrededor de entre los doce y catorce años-, dejará de ser considerado un niño para tomar responsabilidades en actividades económicas y su estado legal (deberes y privilegios) cambiará (1929:93).

En la adolescencia, la cual considera un periodo intermediario como se puede leer, el amor pasional permanecerá, pero no dejará de ser libre. Esto no debe concluir que se trata de una 
sociedad promiscua como lo habían asegurado los evolucionistas, el sufrimiento de un enamorado de la pareja no parece ser tan diferente de la nuestra (1929:94). El antropólogo asevera:

Para el ser humano normal y corriente, sea cual sea el tipo de sociedad en que le encontremos, la atracción en él ejercida por el otro sexo y los episodios pasionales y sentimentales que aquella traerá consigo son siempre los acontecimientos más significativos de su existencia, los más profundamente asociados con su felicidad íntima y el sentido y deleite de la vida (1929:55).

No podría yo asegurar con certeza la aseveración que hace Malinowski pero considero que al menos en nuestra sociedad -a ochenta y cinco años de la publicación de esta obra-, es aplicable, por su puesto con sus evidentes diferencias.

Sin titubear es correcto decir que otro trabajo, -sobre la sexualidad de jóvenes en las consideradas "sociedades primitivas"-, más reconocido que la obra de Malinowski es el de la antropóloga estadounidense Margaret Mead, quien fuera alumna de Franz Boas y Ruth Benedict. ${ }^{3}$

Mead realizó su primer trabajo de campo cuando se trasladó a vivir con los indígenas de Samoa de 1925 a 1933. En su libro Coming on Age in Samoa: A Psychological Study of Primitive Youth for Western Civilization (Adolescencia y cultura en Samoa, 1928) la autora explica cómo y porqué se especializó en las jóvenes adolescentes; buscaba observar toda la cultura a través de la mentalidad de estas mujeres, pues lo que pretendía era comprender el desarrollo del carácter en función de dicha cultura y así como cotejar si la adolescencia era universal, si era una etapa inherente a la biología del ser humano, logrando debatir con Hall sobre dicha universalidad.

En el fondo éste y otros textos de $\mathrm{Mead}^{4}$ responden al objetivo de la antropología en esa época: ¿cuál es el significado y el sentido del comportamiento del otro? Cuando Mead redacta un nuevo prefacio en 1939 para el texto mencionado, reflexionaba sobre el tiempo en que había iniciado el campo. Las preguntas dentro de la comunidad científica giraban entorno a comprender qué era la naturaleza humana y qué tan flexible era. "En aquellos días era importante mostrar que los cambios fisiológicos de la adolescencia no bastaban para explicar el periodo de conmoción y tumulto por el que atraviesan los niños, sino que la facilidad o dificultad de esta transición debía

\footnotetext{
${ }^{3}$ La hija de Mead y del también antropólogo Gregory Bateson escribía en su libro With a Daughter's Eye (Como yo los veía) que su madre y Ruth Benedict tenían una relación más allá de lo profesional, específicamente se refiere al ámbito de lo sexual (Bateson, 1984). Pertinente considerarlo por las posiciones que tomará la autora sobre la libertad sexual.

${ }^{4}$ Growing up in New Guinea: A Comparative Study of Primitive Education (1930) y Sex and Temperament in Three Primitive Societies (Sexo y temperamento en tres sociedades primitivas, 1935) por mencionar sólo dos.
} 
atribuirse a un marco cultural diferente" (1939:14). La autora hace una clara diferencia entre los marcos culturales en Samoa y en Estados Unidos, por un lado, los adolescentes samoanos vivían bajo la libertad sexual, la omisión de responsabilidad económica y la ausencia de presión sobre preferencias mientras que en el país americano el marco cultural hace referencia a una expresión sexual restringida y que se postergaba al matrimonio, a la confusión acerca de los papeles económicos y a las múltiples opciones que el adolescente podía elegir.

La distinción entre ambos marcos culturales y la información recabada a través de la observación la hicieron postular que el modo de ser joven en un contexto determinado implica diferencias sustanciales, rechazando de esta manera el trabajo de los antiguos antropólogos que buscaban rasgos universales. Mead comprobó que la representación que se tenía en Occidente sobre los jóvenes no formaba parte de las que se tenían en Samoa. La autora, de alguna manera y con otras palabras, abría la discusión sobre la pertinencia de hablar sobre juventudes, más que de juventud. Mead hizo visible para cualquiera en Estados Unidos que la adolescencia no podía caracterizarse de la misma manera en contextos diferentes, es decir, no podía generalizarse. ${ }^{5} \mathrm{Al}$ igual que Urteaga,

Me interesa rescatar aquí la actitud teórica de la antropóloga, quien con base en datos de campo cuestiona una definición construida a partir de las, entonces, disciplinas y posturas teóricas hegemónicas en el estudio de las sociedades: la psicología y el evolucionismo organicista que, ahora sabemos, racionalizaron gran parte de los fenómenos sociales emergentes en la modernidad occidental generalizando esas representaciones al resto de las sociedades y las culturas (2011b:14).

Al tiempo que indagaba en las respuestas sobre la naturaleza/cultura humana con los indígenas del archipiélago de Samoa, a través de la comparación de culturas humanas, la antropóloga estadounidense buscaba demostrar que en el estudio de la cultura el antropólogo "está en condiciones de discutir sistemas totales, considerando las ventajas de un aspecto, las desventajas del otro, derivadas de distintas integraciones culturales" (1939:14).

En palabras de Boas, el trabajo de Mead merece especial reconocimiento por mostrar la vida de la juventud samoana, una juventud diferente a la estadounidense. "Los resultados de su empeñosa investigación confirman la sospecha largamente alimentada por los antropólogos, acerca de que mucho de lo que atribuimos a la naturaleza humana no es más que una reacción frente a las restricciones que nos impone nuestra cultura" (1995:36).

\footnotetext{
${ }^{5} \mathrm{Su}$ libros sobre Samoa se popularizaron entre la clase media de Estados Unidos al grado de ser considerados best sellers.
} 
Mucho se puede decir sobre el trabajo que Margaret Mead realizó con los jóvenes durante sus diferentes trabajos de campo. El amor y la sexualidad estuvieron presentes como variables a tratar. El propio Boas, quien supervisaba su trabajo desde la Columbia University, le plantea en una carta -que reproduce en Blackberry Winter. My Earlier Years (Experiencias personales y científicas de una antropóloga, 1972)- sobre los problemas con los que podía encontrarse al trabajar con las jóvenes samoanas:

Otro problema interesante es el de los enamoramientos de las jóvenes. Para las mayores podrías tomar en especial consideración la aparición del amor romántico. Según he podido observar, nunca está del todo ausente y, por supuesto, aparece con más intensidad cuando los padres o la sociedad les imponen matrimonios que las jóvenes no desean (1994b:134).

Pese a las recomendaciones de su mentor, cuando Mead realizó trabajo de campo entre los mundugumor encontró diferencias respecto al tema al igual que en Samoa:

A veces [las niñas] forman uniones temporarias con el fin de buscar aventuras, pero la mayoría de las parejas mundugumor realizan sus acciones en un absoluto secreto. Las consecuencias que pueden derivarse de un asunto amoroso son demasiado peligrosas como para confiar en nadie. (...) Los amores de los jóvenes solteros son súbitos y se hallan fuertemente cargados, caracterizándose por la pasión más que por el cariño o el romance. Unas pocas palabras musitadas con apuro, una cita murmurada al pasar por el camino, son a menudo la única relación que hay entre ellos después que se han elegido, y antes de que esta elección se exprese por el contacto sexual (1935:183).

A diferencia de Malinowski que basaba su trabajo en la teoría de las necesidades desde la Escuela Funcionalista, la antropóloga se concentró en el estudio de la personalidad y la cultura (al igual que Ruth Benedict y Edward Sapir), sus contribuciones por tanto fueron de gran interés para la psicología. Aunque años más tarde sería criticada por la defensa de la "relatividad cultural" que promulgó.

Sin duda, tanto Bronislaw Malinowski como Margaret Mead contribuyeron, desde la disciplina antropológica, al reconocimiento de la diversidad de significados que tanto el amor como la sexualidad tienen según la cultura donde se desarrollen, poniendo en el centro del debate la necesidad de entender que cada grupo social tiene sus propias concepciones sobre la intimidad, el erotismo, los roles de género, la moral, los sentimientos, la reproducción -por mencionar algunos- reconociendo que la sexualidad, además de su dimensión biológica, es una construcción sociocultural, cuestionando de tal manera el determinismo biológico que llegó a predominar en épocas pasadas. 


\section{Los ojos de las ciencias sociales sobre los jóvenes mexicanos}

Por largo tiempo los estudios sobre jóvenes fueron tratados sin mucho interés, la visión del desarrollo humano y la sociabilización de la psicología del siglo XIX imperó al no ser cuestionada ni teórica ni metodológicamente. Es a partir de la década de los ochenta que las ciencias sociales en México vuelven la mirada hacia el estudio de los jóvenes. El conocer la manera en que éstos se perciben y cómo van construyendo una identidad o cultura juvenil se ha puesto en el centro de las discusiones. Hoy día los debates académicos se están adentrando en la búsqueda de herramientas tanto teóricas como prácticas para lograr interpretar lo que significa ser joven en el México contemporáneo, pues todavía hace 13 años, en el 2002, José Manuel Valenzuela Arce escribía con motivo de la interpretación de los datos arrojados por la Encuesta Nacional de Juventud 2000 (ENJ2000) en nuestro país:

sabemos poco sobre cómo estos jóvenes construyen los sentidos de sus vidas, sus hábitos, prácticas sociales, expectativas y necesidades. Tampoco conocemos lo suficiente sobre sus formas de participación social o sobre las diversas maneras como erigen y le otorgan significado a la condición juvenil (...) [pese a que] desde hace más de dos décadas se han realizado estudios sobre las perspectivas y los mundos juveniles (2002:27).

Pese a haberse abandonado como objeto de estudio, a la par de la política económica que derivó en la crisis de la deuda de 1982 que sólo agravó aún más la vida de la población mexicana, las ciencias sociales volvieron la mirada hacia el estudio de los jóvenes. La discusión dentro de éstas había girado en diferentes sentidos. Por un lado se buscó delimitar las edades en que una persona podía considerarse y ser considerada joven; sin duda no se pudo homologar, las investigaciones al respecto demostraron que cada cultura tiene nociones diferenciadas sobre las diversas formas de ser joven. Para Néstor García Canclini:

la noción general de jóvenes presenta la dificultad de delimitar las edades entre las que se extiende. Si el criterio predominante en la bibliografía es fijar el comienzo de la juventud en el final de la educación primaria o el ingreso al mercado laboral, para ciertos sectores el período se inicia en México (y en otros países latinoamericanos) cuando se empieza a trabajar a los 8 ó 10 años. Si para establecer cuándo acaba la juventud se toma el momento en que se deja de vivir con los padres, los estudios europeos, que elevan el final de la juventud hasta los 35 años, dan una respuesta que parece apropiada para muchos mexicanos que siguen con la familia paterna después de los 29 años, edad límite según la Encuesta Nacional de Juventud (2012:7). 
La diferencia no sólo se da entre países, en el nuestro, para efectos del Instituto Mexicano de la Juventud (IMJUVE), encargado de la encuesta mencionada, se maneja el rango de los 12 a los 29 años, a su vez, la Ley de las y los jóvenes del Distrito Federal, que dio origen al Instituto de la Juventud del Distrito Federal (INJUVE), en su artículo 2 delimita el rango de los 14 a los 29 años ${ }^{6}$. Los informes sociodemográficos del Instituto Nacional de Estadística y Geografía (INEGI) marcan la edad de los 15 a los 29 (Patiño, 2012) mientras el Consejo Nacional de Población (CONAPO) lo hace de los 15 a los 24 años al igual que la Asamblea General de las Naciones Unidas (2010:13).

En los hechos, es claro que la juventud no puede clasificarse según un rango de edad fijo, cada cultura tiene significados propios sobre ella, cada grupo espera que sus jóvenes se comporten de una manera específica, como si la condición juvenil no se encontrara en constante reconfiguración.

En la misma línea, hace casi quince años, Roberto Brito presentó la ponencia "Elementos para conceptualizar la juventud" en el seminario La juventud en la Ciudad de México: diagnósticos, políticas, situaciones, retos y desafíos que organizó el área de Investigación y Políticas Juveniles de la Dirección de Programas para la Juventud del Gobierno del Distrito Federal. En este trabajo, Brito afirma que la "juventud" es más que una edad, por tanto, se debe romper con los estereotipos atribuidos a este concepto, ya que de no hacerlo se estaría reduciendo su capacidad como categoría de análisis, pues "nunca podremos encontrar un determinado rango que se adapte a tan diversa realidad" (2000:8). Por su parte, para Rossana Reguillo:

la noción de edad alcanza una densidad que no se agota en el referente biológico, pues adquiere distintas valoraciones entre diferentes sociedades y también en el seno de una misma sociedad. En este sentido, la edad, aunque referente importante, no es una categoría cerrada y transparente: queda relativizada cuando se establecen distinciones principalmente en función de los lugares sociales que ocupan los jóvenes (2012a:23).

Por otro lado, además del "problema" de la edad, por un extenso periodo la juventud se definió como la etapa de transición hacia la vida adulta, por tanto a los jóvenes se les debía instruir hacia los roles de la vida adulta, básicamente éstos giraban en torno a la idea de formar una familia

\footnotetext{
${ }^{6}$ Ley de las y las jóvenes del Distrito Federal, publicada en la Gaceta Oficial del Distrito Federal el 25 de julio del 2000.
} 
propia y recibir un salario producto del trabajo, invisibilizando las necesidades e intereses propios de los jóvenes. ${ }^{7}$ Existe, como comenta Analia Otero:

[una] reformulación del término de juventud como un todo homogéneo, dada la existencia de múltiples formas de habitar la juventud fundamentalmente en relación al sector económico de proveniencia. Al mismo tiempo, remite a la propuesta de abordarla como una fase en sí misma, trascendiendo su consideración como un mero pasaje, es decir, un periodo de preparación para el ejercicio de la etapa adulta (2010:3).

De estas afirmaciones se concluyó que la juventud era un producto de las relaciones de poder, la dominación entre generaciones se hacía presente y no era la juventud la ganadora. El interés de los adultos sobre los jóvenes radicaba en el hecho de quererlos preparar; el aprendizaje sería su única forma de insertarse en la sociedad dejando de lado su papel como actores sociales.

Además de los dos problemas en los que estuvo envuelta la noción de juventud, -y que no se limita a lo escrito-, a lo largo de los últimos treinta y cinco años han habido temas claves sobre los jóvenes y su condición, por ejemplo los de tribus urbanas, culturas juveniles e identidades juveniles, "dentro de las investigaciones que abordan las temáticas generales de la juventud en México (...) [ se encuentran los] análisis de tipo: demográfico, educativo, migratorio, de salud, drogadicción, adicciones, participación política, género, violencia, juventud rural, religión y valores juveniles" (Mendoza, 2011:214).

Urteaga comenta que la noción de culturas juveniles ${ }^{8}$ fue "vital para reintroducir al sujeto joven como actor y poder hacer audibles las voces de los segmentos juveniles marginados de la investigación social" (2011a:19). A partir de esta noción se abrió paso a la heterogeneidad cultural de las personas jóvenes y a su agencia como la capacidad de intervenir en ámbitos que habían sido exclusivos de los adultos.

Ya no estamos en los tiempos de Malinowski ni Mead, ni la antropología está abocada a sociedades homogéneas y territorializadas como se declaraba en las primeras décadas del siglo pasado por lo que considero necesario escribir, de manera muy breve, el contexto actual en que estamos trabajando.

\footnotetext{
${ }^{7}$ La Encuesta Nacional de Juventud 2010 (ENJ2010) es partidaria de esta idea: "La juventud es una etapa de transición entre la niñez y la adultez, caracterizada por múltiples cambios en todos los aspectos de la vida. El hogar y la dinámica familiar de los jóvenes representan el punto de partida en la búsqueda de la consolidación de su trayectoria de vida" (ENJ, 2010:9).

8 "Conjunto de experiencias sociales expresadas colectivamente para los jóvenes mediante la construcción de estilos distintivos, localizados fundamentalmente en tiempos y/o espacios no institucionales” (Urteaga, 2011a:19).
} 


\section{Un vistazo a la situación actual de los jóvenes en México}

Bajo la lógica de la dicomotía local/global algunos estudios sobre juventud se han centrado en explicar procesos micro o locales que han dejado de lado el contexto político y económico que sin duda repercute en las biografías de los jóvenes. Por el otro, los trabajos que tratan de explicar la situaciones de éstos a nivel macro o global se olvidan de las luchas cotidianas que dan los jóvenes buscando la estabilidad positiva que el capitalismo no produce sino al contrario que recrudece. Valenzuela hace una crítica oportuna a los trabajos sobre las identidades juveniles y que podría aplicarse en definitiva a otras investigaciones:

Durante los últimos años hemos observado un importante énfasis en los estudios sobre identidades e identificaciones juveniles. Desafortunadamente, en muchos casos pareciera que la juventud fuera un sector autocontenido y que se explicara desde "lo juvenil", sin importar sus articulaciones y sus contextos sociales. Las identidades juveniles deben ubicarse desde contextos amplios, por lo cual no pueden analizarse de manera específica a partir de la condición juvenil, pues éstas se conforman en ámbitos relacionales y se encuentran atravesadas por procesos de identificación a escala más amplia. Es importante evitar el aislamiento o la atomización de la condición juvenil, como si ésta fuera externa a otros fenómenos sociales, por ello es necesario ubicar estos procesos de identificación juvenil dentro de marcos interpretativos que nos permitan entender la manera más adecuada la especificidad de lo juvenil, sin perder de vista la relación con los contextos socioculturales complejos que enmarcan los grandes cambios de las sociedades contemporáneas. (...) La condición juvenil y la juventud, más que meras palabras refieren a relaciones sociales históricamente situadas y representadas que conforman umbrales semantizados de adscripción y diferencia inmersos en redes y estructuras de poder (2002:29-30).

Es necesario empezar diciendo que la crisis del régimen se ve representada, entre otros, en los hechos ocurridos entre el 26 y 27 de septiembre del año pasado en la ciudad de Iguala, Guerrero, donde fueron asesinadas seis personas (de las cuales cuatro eran jóvenes, y a su vez, tres de ellas normalistas), heridos 21 normalistas (uno de ellos condenado a una vida vegetativa) y donde fueron secuestrados 43 más, todos estudiantes de la Escuela Normal Rural Isidro Burgos de Ayotzinapa que se encontraban recolectando recursos para poder asistir a la marcha del 2 de octubre en la Ciudad de México. Estos ataques, acompañados de resistencia, en este caso la explosión social de la juventud estudiantil que se ha producido como respuesta a la barbarie han abierto una nueva etapa en la situación política del país; han agudizado una crisis política nacional sin precedentes. Pero no se trata de una crisis más, se trata de la crisis del régimen, como mencioné anteriormente. Han pasado casi nueve meses y aún no hay castigo a los culpables, no 
hay explicaciones, no hay evidencia científica sobre el paradero de los estudiantes; nueve meses que la población, con sus altibajos, sigue exigiendo justicia a nivel nacional.

La violencia desatada por el narco en contubernio con el Estado mexicano, anterior a Ayotzinapa, había llenado, y lo sigue haciendo, los títulos de los periódicos locales y nacionales, en la prensa internacional lo dicho sobre México mucho tiene que ver con la violencia que se desató principalmente en el gobierno de Felipe Calderón y que sigue agravándose en el mandato de Enrique Peña Nieto a raíz de la aprobación de las contrarreformas estructurales (energética, laboral, educativa, comunicaciones, etcétera).

Junto a la violencia, hay otros aspectos fundamentales para el desarrollo de las juventudes mexicanas que no están siendo atendidas, como la educación y el trabajo. El periódico $L a$ Jornada, el 24 de noviembre, difundió la nota "Pobres, 45\% de jóvenes mexicanos, pero gobiernos recortan apoyos". Los datos están plasmados en el documento Invertir para transformar: la juventud como protagonista del desarrollo, que elaboraron en conjunto la Comisión Económica para América Latina (CEPAL), la Organización Iberoamericana de Juventud (OIJ) y el IMJUVE.

Frente a la pobreza que enfrenta 44.9 por ciento de los jóvenes mexicanos de 12 a 29 años de edad (grupo constituido por 16.6 millones de personas), la inversión pública que se les destina en aspectos como educación y salud se ha reducido en los últimos años (...). El análisis destaca que México ocupa el quinto lugar con mayor porcentaje de jóvenes en pobreza entre 16 naciones de América Latina y el Caribe, sólo superado por Honduras, Paraguay, El Salvador y República Dominicana. (...) Uno de cada dos jóvenes mexicanos ni siquiera cuenta con los ingresos suficientes para adquirir una canasta básica (incluye bienes no alimentarios) (González, 2014:24).

A lo anterior se agrega que la cuarta parte de los jóvenes carece de acceso a los servicios de salud, 68.4 por ciento no tienen seguridad social, y la quinta parte no puede contar con servicios básicos de vivienda.

Ayotzinapa, como el resto de los hechos descritos, ha puesto al descubierto la profunda crisis del régimen tras años de aplicación de políticas de pillaje de nuestro país por el capital financiero: privatizaciones, tratados de libre comercio, contrarreformas estructurales y destrucción de los derechos de los jóvenes y trabajadores. Treinta años de empobrecimiento de la población, de desmantelamiento de la industria nacional y de la agricultura para el consumo interno han desarrollado el negocio de las drogas-armas y con ello la violencia, la descomposición de la sociedad y la profunda corrupción del Estado priista, Estado-narco. 
Ésta es la situación en que viven los jóvenes del país, éste es el contexto donde se encuentran realizando sus biografías. Como menciona García Canclini: "El presente y el futuro de los jóvenes se configuran entonces, como el de muchos otros, al modo de un paisaje desencantado. Pero no para todos idéntico, como sabemos" (2005:171). Igualmente Reguillo argumenta que existen dos tipos de juventudes, por un lado existe una juventud mayoritaria, precarizada, que no cuenta con ningún tipo de seguridad social en su vida, se encuentra alejada de las instituciones y sobrevive con los mínimos. Por el otro, se localiza el antónimo a esta caracterización: una juventud minoritaria que se encuentra conectada e incorporada a las instituciones y que además está en condiciones de elegir (2012b:401).

Ejemplo claro de estos dos tipos de juventudes se percibe en el informe de la CEPAL. Así lo destacó la revista Proceso en su nota "Más de 50\% de jóvenes mexicanos vive en la pobreza: Cepal”. En ésta, se presentan algunos datos que merecen ser mencionados:

De los 38.9 millones de jóvenes mexicanos, de 12 a 29 años, seis millones viven en una situación de indigencia, (...). A raíz de una estimación del presupuesto otorgado por el Estado mexicano de manera específica a los jóvenes, el estudio revela que el país redujo su gasto público en educación (...). Luego, advierte: "Si somos coherentes con el discurso de jóvenes como actores estratégicos para el desarrollo y con la viabilidad del país en el futuro, si la inversión no se destina con más eficacia hacia jóvenes, estos datos son más que elocuentes respecto a la disociación entre la acción y el discurso". El análisis señala que $70 \%$ de los jóvenes mexicanos carece de acceso a la seguridad social, $30 \%$ a los servicios de salud y $15.3 \%$ se encuentra en situación de rezago educativo, mientras que más de la mitad de la población desempleada en el país tiene este rango de edad. La tasa de desempleo de los jóvenes se elevó a $7.7 \%$ en 2013, muy por arriba del promedio nacional de $4.6 \%$ (Tourliere, 2014).

Las anteriores líneas sólo confirman la precariedad en la que vive una juventud mayoritaria en el país; por un lado, se criminaliza la protesta social, se asesina con total impunidad, se violan todos los derechos humanos y garantías individuales, se ataca a la clase trabajadora y a la juventud, se reduce el presupuesto para educación, salud, vivienda, transporte y otros servicios que deben ser proporcionados por el Estado; y por el otro, se le niega un trabajo digno con derechos y prestaciones, con seguridad social, con derecho a un sindicato independiente. Ante esta situación es inevitable que no exista movilidad social para los jóvenes, independientemente de que tengan más estudios que sus padres. Esta caracterización de la vida nacional tiene gran similitud con la realidad de otros países, tanto en lo que respecta a las agresiones contra la mayoría de la población como por la resistencia de esta misma, por ejemplo, con sus respectivas 
particularidades, Brasil y Chile ilustran al igual que México, las consecuencias de una serie de ajustes estructurales dictados por el imperialismo.

Es fundamental que aquellos que estamos interesados en el desarrollo teórico y empírico sobre los jóvenes tomemos en cuenta el contexto sociohistórico, las estructuras y las particularidades del caso. Para Reguillo, en el plano estructural el núcleo de desigualdad entre los jóvenes mexicanos se relaciona con las alternativas que tienen que elegir al momento de construir sus vidas y con el acceso a las instituciones que ayuden a construirlas con un mínimo de certeza del futuro. La realidad es clara: pobreza, migración, desigualdad, violencia, desempleo, trabajo informal y explotación (2012b).

\section{Estudios enfocados en la vida amorosa y sexual de los jóvenes mexicanos}

Abarcados en los dos apartados anteriores, de manera breve, la situación económica, política y social en la que se encuentran los jóvenes mexicanos así como los estudios más sobresalientes sobre éstos me gustaría introducir un tema que está presente ante los ojos dormidos de las investigaciones, me refiero a la vida amorosa y sexual de los jóvenes.

Como mencioné al inicio de este trabajo, estos tres elementos (amor, sexualidad y jóvenes) permanecieron ausentes de las pesquisas en nuestro país pero sin duda son temas que deben ser contemplados.

Existen diversos datos sociodemográficos que ayudarán a resaltar la importancia de que los estudios sobre jóvenes vuelquen su mirada a la vida amorosa y sexual de éstos. Según cifras del Censo de Población y Vivienda 2010 del INEGI en México existen 36.2 millones de jóvenes entre 12 y 29 años. De ellos 18.4 (50.8\%) son mujeres y 17.8 millones (49.2\%) son hombres. El 52.9\% de estos jóvenes se concentra en 8 estados del país (Estado de México, Distrito Federal, Veracruz, Jalisco, Puebla, Guanajuato, Chiapas y Michoacán). De estos 36.2 millones a nivel nacional, 11 millones se concentran entre los 15 y 19 años, 9.9 millones en el rango de 20 a 24 años, 8.8 millones entre los 25 y 29 y 6.5 millones se concentra entre los 12 y 14 años.

En México, datos de la Encuesta Nacional de Discriminación 2010 (ENADIS 2010), reflejan que cerca de la mitad (49.51\% de 12 a 17 años y $51.70 \%$ de 18 a 29 años) de la población joven considera que en el país no se respetan sus derechos. Poco más de esa misma población (53.43\% de 12 a 17 años y $51.79 \%$ de 18 a 29 años) considera que la sociedad no conoce sus problemas y por ello no les ayuda. 
La anteriormente mencionada ENJ2010 dedicó una parte al noviazgo, la sexualidad y la procreación. Por ejemplo, comenta que en cuanto a lo que las personas jóvenes platican con sus novios (as), los resultados muestran que $69.7 \%$ charlan sobre sexo, los temas más hablados son los referentes a los amigos y al futuro.

Por otro lado, en la Encuesta Nacional de Valores en Juventud 2012, el 57.7\% de los jóvenes reconoció haber tenido relaciones sexuales a diferencia del $42.3 \%$ que no. Según menciona la Encuesta, en el país se puede hablar de un mapa cultural de la sexualidad, pues existen diferencias regionales en cuanto a la actividad sexual, por ejemplo, la región centrooccidente es más conservadora que región centro. Los hombres siguen siendo, como en tiempos pasados, los que inician antes que las mujeres: ellos a los 16 y ellas a los 17 años. $4.3 \%$ de quienes contestaron la Encuesta dijeron haber tenido su primera relación sexual con una persona de su mismo sexo.

Debido a la inclinación por empezar a temprana edad las relaciones, la Encuesta considera pertinente preguntar sobre las prácticas anticonceptivas de los jóvenes en el país. El 66\% de los jóvenes sexualmente activos utiliza algún método mientras $32.4 \%$ no lo hacen. Las edades que tienen los jóvenes que más usan algún de éstos va de los 20 a los 24 años. Y entre mayor escolaridad más asciende su uso. Del total de los jóvenes que notificó haber tenido relaciones, $46.1 \%$ de los hombres y $32.8 \%$ de las mujeres reportaron que no les gusta usar ningún método. Además $36.3 \%$ de las chicas había estado embarazada por lo menos una vez.

La Encuesta afirma que las relaciones de pareja son fundamentales para los jóvenes pues durante esta "etapa" se presentan las primeras experiencias de pareja y de noviazgo. En los valores que los jóvenes consideran importantes para que haya éxito en la pareja se encuentran la fidelidad (83.8\%), la comprensión y la disponibilidad a resolver los problemas de pareja. Igualmente importante es mencionar que el $66 \%$ de los encuestados reportó que es determinante un entendimiento a la hora de tener relaciones sexuales.

Estos datos dan una muestra clara de la importancia de la necesidad del estudio de la vida sexual y amorosa de los jóvenes en México, a mi parecer, desde una perspectiva antropológica. Las investigaciones deben tener por objetivo el conocer las prácticas cotidianas, aquellos aspectos sentimentales y sexuales de los jóvenes que en muchas ocasiones se dan por sentados, suscitando únicamente una desinformación referente a una parte de la población que se encuentra en un constante proceso de reconstrucción lleno de polémicas. El amor y la sexualidad son elementos 
centrales de su desarrollo. La juventud mexicana se encuentra en una coyuntura identitaria, en un momento de creación de nuevas opciones para interrelacionarse, de intimar, de amar, de vivir. La antropología, como una ciencia con los fundamentos teóricos y metodológicos necesarios, puede aportar al conocimiento sobre la vida y los deseos de los jóvenes. Concuerdo con Zeyda Rodríguez Morales cuando afirma que

Poner atención a las formas de vivir la afectividad entre los jóvenes en la época contemporánea permite acercarse a los procesos de subjetivización de forma privilegiada (...). En primer término, en virtud de la oleada conservadora de los últimos años, se han explicitado con mayor fuerza algunos discursos y se han puesto en marcha diversas acciones que se han centrado especialmente en el sector juvenil de la población. Dirigirse a los jóvenes a partir de visiones moralizadoras o liberadoras, denota los afanes de diversas instituciones por educar o formar sujetos que se consideren aún maleables. Esto constituye una buena oportunidad para analizar los discursos que de suyo son mucho más difíciles de observar y desentrañar (2006:19).

Los resultados de las encuestas mencionadas no permiten de manera clara analizar esos discursos a los que se refiere Rodríguez. El propio José Manuel Valenzuela cuando escribe algunos porcentajes de jóvenes que han tenido novio(a), arrojados por la ENJ2000, reconoce que existe poca información sobre el significado del noviazgo para los jóvenes mexicanos:

poco sabemos de los sentidos precisos de lo que implican los noviazgos entre los jóvenes [pese a lo anterior reconoce que] podemos considerar que existen diversos puntos de vista y formas de vivirlos, lo cual que expresa en los grados de la permisividad en la expresión física de los afectos (2002:38).

Este vacío teórico y empírico sobre las juventudes, también se encuentra presente en el estudio sobre los imaginarios y las prácticas amorosas entre jóvenes, según Reguillo "se trata de un tema prácticamente ausente en las reflexiones y estudios empíricos que han conformado el vigoroso debate mexicano (y latinoamericano) en torno a los jóvenes” (2006:13). La antropóloga Edith Calderón Rivera corrobora lo dicho por Reguillo con el simple título de su obra La afectividad en antropología. Una estructura ausente (2012). La antropología necesita enfrentarse y apostar por el estudio de las subjetividades de la vida social, conocer estos aspectos de la vida juvenil puede ayudar a hacerlo.

En cuanto a los trabajos que indagan sobre la sexualidad de las personas jóvenes, éstos se enmarcaron, junto con los de demografía y adicciones, a una categoría que abarcaba al trío: el estudio de la salud juvenil. La sexualidad se enfocaría a partir de cuatro aproximaciones 
disciplinarias: 1) Los estudios sociodemográficos: en una primera etapa abarcaban el conocimiento sobre patrones reproductivos, las prácticas sexuales en riesgo, enfermedades de transmisión sexual y el uso de anticonceptivos; en una segunda etapa se agregaron estudios sobre el aborto, los derechos reproductivos, la masculinidad y la homosexualidad; 2) Los médicos y epidemiológicos se centraron en la salud de ciertos grupos de jóvenes; 3) Los psicosociales y antropológicos: la psicología abarcó los trabajos referentes a las mujeres jóvenes con una vida sexual activa y desde la antropología el interés se volcó al estudio de los jóvenes rurales e indígenas, y 4) Los demoantropológicos. Más adelante otra vertiente de análisis con relación a la sexualidad fue el género. Esta categoría empezó a darle otro significado a los estudios de salud reproductiva, como el embarazo adolescente, los derechos sexuales y reproductivos, las enfermedades de transmisión sexual y la maternidad. Aún más recientemente se agregó el tema de la masculinidad (Mendoza, 2011:208-211).

A continuación traigo a la discusión algunos trabajos realizados sobre la vida amorosa y sexual de los jóvenes casi todos ellos editados en este nuevo siglo.

Por un lado, Ana María Ramírez Herrera escribe en la publicación Estudios Michoacanos del Colegio de Michoacán "Honor, moral y sexualidad en la cultura purhépecha: reglas y normas de comportamiento en las relaciones de pareja" (2003), en él, expone como existen comportamientos y actitudes diferentes para hombres y mujeres que están regidas por el discurso de la moral y la sexualidad del pueblo de San Francisco Cherán que se convierten en costumbres que deben seguirse o de lo contrario aquellos que la quebranten serán sancionados. La autora parte de la identidad de género para explicar cómo es que se deben comportar las jovencitas, sobre todo en edad casadera, pues son las que se encuentran en un peligro constante en el que pueden perder su honor y por tanto el de su familia. Dentro de este marco es en el que la autora relata los lugares y tiempos que son adecuados para practicar el noviazgo, pues de no hacerse así, las jóvenes se vuelven el centro de atención de habladurías, lo que en cierto momento podría afectarles a la hora de querer contraer matrimonio.

En "Identidad, adolescencia y cultura. Jóvenes secundarios en un contexto regional" Josefina Díaz Sánchez Díaz (2006) tiene como objetivo mostrar los elementos con los cuales los jóvenes estudiantes de secundarias marginales del municipio de Tejupilco en el Estado de México construyen su identidad. Según Díaz, los jóvenes construyen ésta en función de su autonomía, así como sus propios valores y proyectos. Entre los elementos que da la autora se encuentran la 
intimidad y las manifestaciones de sexualidad, que son experimentados principalmente durante el noviazgo, que a su vez es experimentado durante la adolescencia, momento en que se dan las primeras relaciones afectivas fuera de la familia. El texto de Díaz da cuenta en parte de la opinión que tienen los jóvenes sobre el noviazgo, las incertidumbres y temores que surgen en él. Parte de la riqueza de su trabajo recae en que aunque admite que existen diferencias entre las opiniones de hombres y mujeres remarca que el noviazgo es una relación importante para ambos y no cae en el error de considerarlo importante sólo para las mujeres.

Tuñón, Ayús y Montejo realizan un interesante texto que habla sobre cómo la sexualidad juvenil es un campo de significados que necesitamos conocer. Para los autores es necesario compenetrar "en la lógica propia del sentir y el vivenciar el tema por los jóvenes, dar cuenta de los aspectos silenciados pero presentes de su ejercicio" (2004:55). A través de una propuesta que combina los enfoques cuantitativos y cualitativos, los autores desean profundizar en los procesos de construcción de los significados sexuales que tienen sobre la sexualidad los jóvenes y de la negociación de los mismos. Para ellos los significados de las sexualidades no pueden enmarcarse en los actuales discursos educativos, clínicos, políticos ni académicos porque no siempre coinciden, o lo hace sólo parcialmente, con las representaciones que les dan los jóvenes.

Uno de los trabajos que me parece de lo más enriquecedor es el Carmen Ilizarbe "Todavía no somos quienes queremos ser. Construcciones sociales del amor y la pareja en jóvenes de sectores medios de Lima" (1999). El trabajo de Ilizarbe, más que cualquiera de los trabajos anteriores, tiene como objetivo el acercarse a las opiniones que tienen los jóvenes de este sector urbano sobre el amor y la pareja. En la investigación Ilizarde se reveló con que los jóvenes se encuentran inmersos en una cultura amorosa y del romance que los ha llevado a idealizar un tipo de amor y de relaciones de pareja que choca con las situaciones a las que se enfrentan; sus experiencias son distintas y en medio de situaciones que no saben cómo manejar, a pesar de que los medios de comunicación, la escuela y la familia, les dicen cómo hacerlo, es que surgen vivencias que les ayudan a reconfigurar su opinión sobre el amor.

La hipótesis de Ilizarde es que los jóvenes del sector medio de Lima están inmersos en dos modelos de amor: el amor romántico y el amor confluente. Estos dos modelos en los que se encuentran los jóvenes están marcando pautas de comportamiento en sus relaciones de pareja. Además de estos tipos de amor, los jóvenes han crecido bajo la idea de que hombres y mujeres 
son diferentes, por lo que las relaciones de género y las disputas por el poder juegan un papel determinante para sus relaciones de noviazgo.

En México, trabajos como los de Gabriela Rodríguez con Benno de Keijzer y los de Zeyda Rodríguez son dos que considero relevantes sobre los temas de interés. El trabajo de Rodríguez y De Keijzer que describen en su libro La noche se hizo para los hombres (2002) fue realizado en una comunidad del sur de Puebla y refleja un hecho trascendental, el surgimiento de una etapa que no se conocía: la adolescencia, etapa en la que los jóvenes tienen la oportunidad de vivir un noviazgo no terminal, muy distinto al que tuvieron sus padres y abuelos. En medio del cortejo y estos noviazgos sin miras al matrimonio, los jóvenes campesinos tienen la oportunidad de disfrutar una etapa de conocimiento del otro, de goce, de caricias, besos y erotismo, donde la sexualidad juega un papel primordial, pues también ha tenido sus transformaciones pero donde continua arrastrando un velo muy pesado, pues los tabús y prejuicios no permiten a los jóvenes platicar y preguntar de la manera correcta sus dudas, por lo que les toca a ellos experimentar y en muchas ocasiones sufrir las consecuencias de la ignorancia o irresponsabilidad sobre el tema. Para los autores conocer las prácticas sexuales de los jóvenes a través de su voz significa poder desarrollar estrategias ante los problemas de morbimortalidad, además de poder conocer las contrariedades que tienen que ver con las frustraciones que pueden generarse por vivir una sexualidad reprimida y sin conocimiento.

Los autores dedican 250 páginas para explicar cómo fueron y cómo son las relaciones de cortejo, noviazgo y sexualidad, no sólo entre generaciones sino entre géneros en esta comunidad poblana donde la migración hacia Estados Unidos ha aumentado cada vez más. Ambos investigadores están interesados en los estudios juveniles para conocer la perspectiva de este grupo, y así sacar conclusiones para crear programas y políticas públicas que puedan incidir en sus problemáticas, en este caso por ejemplo, la educación sexual.

Mientras Rodríguez y De Keijzer se enfocaron más a temas de sexualidad, Zeyda Rodríguez presenta, a mi parecer, uno de los mejores trabajos sobre afectividades en la población juvenil. En su libro Paradojas del amor romántico. Relaciones amorosas entre jóvenes (2006) Rodríguez Morales inicia marcando que los fenómenos amorosos y sexuales ameritan mayor interés, pues para empezar poseen una dimensión política que es del interés de la investigación social "pues aunque transcurren en el espacio de lo íntimo, tales experiencias se encuentran en el 
centro de la disputa social cuya preocupación fundamental se ubica en la definición del tipo de sujetos que diversas instituciones se plantean en las sociedades contemporáneas" (2006:19).

Concuerdo con Rodríguez al caracterizar a los jóvenes como agentes sociales. Éstos sin duda tienen la capacidad de intervenir, movilizar y reconfigurar prácticas y representaciones así como crear narrativas que demuestran que luchan por desligarse de los imaginarios amorosos y las prácticas sexuales de pasadas generaciones para crear nuevas formas de afectividad y del ejercicio de su sexualidad. Estos cambios de ninguna manera han dejado de parecerse del todo a las de los que ahora son adultos, en realidad aquí es cuando empiezan los conflictos y la lucha por la propia identidad amorosa y sexual de los jóvenes,

en la época de cambio acelerado que estamos viviendo, esta transmisión de saber [intergeneracionalmente] es absolutamente insuficiente. Es por ello que no sorprende que el grupo de pares, la propia generación aterrizada en los agrupamientos delineados por la adscripción educativa, laboral, cultural, cobre especial relevancia. Las evidencias indican que los jóvenes comparten entre ellos mismos un saber producido por las experiencias amorosas vividas, las cuales son tomadas como modelos o patrones, que dan lugar a una transmisión horizontal que se conjuga con el saber de los padres (2006:24).

La investigación de Rodríguez con jóvenes de clase media en Guadalajara mostró que las nociones que tienen los jóvenes tanto del amor como de la sexualidad son construcciones sociales y por tanto los imaginarios y las prácticas han variado a lo largo de la historia.

Rodríguez Morales y María Martha Collignon, en un trabajo que realizan juntas, retoman esta idea explicando que a lo largo del siglo XX han existido diferentes "estilos de amar" en México. Su trabajo expone como en cada época histórica las dimensiones de lo sexual y lo amoroso se articulan de diferente manera. Las autoras proponen la noción de "régimen erótico" para explicar estos estilos de amar. El primero de ellos duraría hasta los años cincuenta y tenía se herencia en el siglo XIX. El segundo abarca de los años sesenta a los ochenta y el último tuvo sus inicios en los noventa y aún no ha dado paso a un cuarto régimen erótico, más bien se prepara. Dejando de lado una visión evolucionista admiten que

en ciertos momentos históricos, aparecen organizados, por su parte, elementos simbólicos que inciden directamente en las identidades de hombres y mujeres que aman, se erotizan y tienen relaciones sexuales fundadas en ciertos moldes; instituciones que poseen diferentes grados de poder; saberes científicos y religiosos que proporcionan concepciones sobre el cuerpo; mientras que, por otra parte, se despliega una serie de prácticas individuales que manifiestan su resistencia o su sumisión, su acoplamiento o desacoplamiento, respecto a este conjunto de cosas (2010:262). 
Anterior a este trabajo, Collignon ya había especificado que existe una contradicción entre las apreciaciones que los jóvenes tienen sobre la socialización y educación sobre sexualidad que han recibido con lo que históricamente se ha construido. Por un lado, la crisis del sistema económico y por otro el acceso a la tecnología y la circulación de mensajes deben hacernos replantear las investigaciones que sobre jóvenes y sexualidad realizamos. Para Collignon los medios de comunicación juegan, a la par de la familia, la escuela y los amigos, un lugar central en el conocimiento de las percepciones y valores que los jóvenes tienen sobre la sexualidad. Además, para la doctora en Ciencias Sociales, la participación por parte de los jóvenes en actividades colectivas los hace visibilizarse y visibilizar.

Los jóvenes mexicanos y su sexualidad no están exentos de ser mirados ni de mirar, de conocer lo que la sexualidad es y significa para jóvenes de distintas culturas - no sólo de países distintos del propio sino de grupos diferentes aun dentro de la misma sociedad y país que se habita (2003:46).

Por último, merece especial atención el trabajo que realizan Urteaga y Mauricio Sáenz en Juventudes, géneros y sexos. Resituando categorías (2012). Sin duda es un texto por lo más sugerente por su propuesta pertinente en cuanto al uso de las categorías analíticas género, cuerpo, sexo y jóvenes pues éstas, aseguran, ofrecen la posibilidad de formular innovadores objetos de estudio desconocidos de lo juvenil contemporáneo, como por ejemplo el papel del "sexo" en la conformación identitaria de los jóvenes; el ejercicio de la sexualidad relacionado con el placer y el deseo y no con fines reproductivos o las relaciones entre "sexo", juventud, clase social y etnia, por mencionar algunos.

Desde mi punto de vista, si a esta propuesta se le añade las categorías amor y afectividad aún más se enriquecería el conocimiento sobre los jóvenes contemporáneos ya que incluso en nuestros días y pese a los cambios en nuestra cultura tanto amor como sexualidad siguen estando íntimamente ligados. A las variables propuestas por los autores vendría bien agregar los sentimientos.

El trabajo de los antropólogos de la Escuela Nacional de Antropología e Historia (ENAH) es un esfuerzo teórico que concluye invitando a la discusión sobre cómo los investigadores podemos acercarnos a esta rubro de la vida de los jóvenes. Justo ésta es la parte con la que me gustaría proseguir, 
consideramos necesarias las aproximaciones teórico-metodológicos múltiples en torno a este campo amplio y vital para el entendimiento de los jóvenes y sus juventudes contemporáneas, en el cual es muy probable que se encuentre otra clave para que los jóvenes dejen de ser considerados como la encarnación de la disonancia (2012:19).

Parte de los textos mencionados son meramente teóricos, mi apuesta es hacer una discusión y una propuesta metodológica sobre cuál podría ser una alternativa más para trabajar de manera directa con los jóvenes y poder, a partir de un trabajo en conjunto, entre investigador e interlocutores, encontrar códigos culturales, contradicciones y tensiones que rigen el comportamiento amoroso y sexual de los jóvenes.

\section{Otras formas de observar}

Cuando Bronislaw Malinowski escribió sobre su trabajo de campo en las Melanesias siempre tuvo presente que era necesario no sólo incluir en los textos los resultados de la pesquisa, sino

que al mismo nivel se encontraba describir y explicar los métodos que había utilizado para la recolección del material etnográfico. Su propuesta, aún vigente para unos, reformulada y refutada por otros, consiste en vivir por largos periodos con los habitantes de un grupo culturalmente opuesto para poder observarlos el mayor tiempo posible, es necesario que se aprenda la lengua y adentrarse lo más posible a su cultura. A partir de la observación Malinowski consideraba debían realizarse etnografías en las que se registraría lo que se observaba y las interpretaciones que el etnógrafo hacía de ellas.

Considero que una fuente etnográfica tiene valor científico incuestionable siempre que podamos hacer una clara distinción entre, por una parte, lo que son los resultados de la observación directa y las exposiciones e interpretaciones del indígena, y por otra parte, las deducciones del autor basadas en su sentido común y capacidad de penetración psicológica (1922:40-41).

Para lograr escribir tan bastamente sobre la vida sexual de los trobriandeses, Malinowski realizaba historias de vida sexual de parejas que considerara representativas a través de descripciones sistemáticas de las diferentes fases por las que hombres y mujeres pasan entre la infancia y la madurez. Aun así, en un contexto donde las relaciones amorosas y sexuales no se remitían a la vida privada e íntima de las parejas, el propio Malinowski reconocía que cuando la observación estaba enfocada a descifrar estos temas no siempre era fácil hacerlo: "La observación 
directa es difícil siempre que se trate de estudiar la atracción sexual y el desarrollo de una pasión y hasta es imposible a menudo, y en gran parte se ve uno obligado a contentarse con lo que las confidencias y la chismografía le enseñen" (1929:221). El hecho de que fuera difícil no desalentaba al autor de afirmar que no había mejor método que la observación directa prolongada, por lo mismo era vital aprender su lengua y buscar crear el mayor número de relaciones personales; la información que derivara de esta manera consideraba era sin duda más útil que las que se obtenían, a su ver, mecánicamente, a través de respuestas para cuestionarios establecidos de antemano. Malinowski siempre prefirió estimular confidencias espontáneas y conversaciones íntimas frecuentes.

Sin duda los aportes de Malinowski a la ciencia antropológica tanto teóricos como metodológicos son indiscutibles pero también es innegable que la situación de los jóvenes contemporáneos poco se asemeja a los estudiados a principios del siglo XX. A lo largo de su historia la disciplina antropológica ha pasado por incertidumbres y vacíos teóricometodológicos que no han podido responder a las necesidades de los tiempos y las poblaciones. Desde que ésta reconstruyó su objeto de estudio: todas las sociedades y no sólo las mal llamadas "exóticas" ha tratado de colaborar transdisciplinariamente bajo la idea de conocer integralmente cómo se está llevando la interculturalidad en el mundo actual tan acelerado en el que se desdibujan en muchos casos las fronteras culturales al mismo tiempo que en otras se refuerzan.

Justo en estos tiempos, en el que los jóvenes del siglo XXI se caracterizan por disponer de una amplia oferta mediática: televisión, radio, teléfonos celulares, computadoras, cámaras fotográficas, que les ofrecen espacios, bienes culturales, capitales simbólicos y formas de socialización (Morduchowicz, 2008) parece pertinente que la antropología se enfoque a otros horizontes, por ejemplo, al valor antropológico que tienen las imágenes. Por supuesto que tampoco estamos hablando de algo nuevo en la antropología, pero quizá sí poco difundida en nuestro país en años anteriores, me refiero a la antropología visual. Ésta pese a lo que se piensa, no es una disciplina nueva, académicamente tiene sus orígenes prácticos en el propio nacimiento de la fotografía y del cine en siglo XIX. ${ }^{9}$

\footnotetext{
${ }^{9}$ Llama la atención que tanto Malinowski como Mead utilizaron en sus diferentes trabajos de alguna u otra manera la antropología visual. Por un lado Malinowski reconoce el uso de la fotografía como parte de la investigación etnográfica; en Los argonautas narra que su profesor Seligman lo equipó “con un fonógrafo, una cámara fotográfica, instrumentos antropométricos y demás parafernalia que requiere el trabajo etnográfico" (1922:32). La edición de 1975 de la obra La vida sexual contiene 92 fotografías que sin duda ayudan a tener una visión más amplia de este
} 
Para el antropólogo Antonio Zirión la antropología verbal y la antropología visual proporcionan saberes diferenciados, la pertinencia del uso de ambas recae en saberlas utilizar para ampliar tanto el conocimiento sobre "el otro" como para desarrollar un diálogo intercultural. Es necesario reconocer el valor antropológico que tienen las imágenes así como partir de la idea de que la antropología visual es una especialidad transdisciplinaria "Al establecer un diálogo con el mundo de la imagen, la antropología se perfila como una disciplina acaso más libre y abierta, marcadamente cualitativa y creativa, alejada de las estadísticas, cuestionarios, entrevistas formales y estudios cuantitativos, propios de una vocación cientificista.” (Zirión, 2015:48). Además lo es en el sentido de que en la antropología visual concurren las artes visuales, el cine, la fotografía, entre otras, dándose un diálogo entre las humanidades y las artes.

Para el antropólogo y documentalista, la imagen en sí "es un auténtico vehículo de conocimiento; representa una forma distinta de observar, de acordar y analizar la cultura y la sociedad" (2015:48) y por tanto puede decirse que la antropología visual es un modelo alternativo de producir saberes. La antropología visual puede reconocerse en el momento que la imagen, fija o en movimiento, provoca interés o curiosidad.

Bajo estos argumentos la antropología visual puede ayudar a comprender las discontinuidades y las rupturas de las concepciones y prácticas de la vida amorosa y sexual de los jóvenes; por medio de la etnografía colaborativa se profundizar en aquellos aspectos íntimos que las herramientas cuantitativas no podrán dar a conocer.

grupo étnico. De hecho quien lo auxilió en el trabajo fotográfico fue su amigo Billy Hancock quien fuera comerciante de perlas en las Islas Trobriand además de ser quien le proporcionara diferentes tipos de ayuda.

El caso de Mead es aún más especial pues fue justamente ella quien acuñó el concepto de antropología visual en los años cuarenta. Desde su primer trabajo de campo en Samoa ésta llevaba "una moderna máquina fotográfica" (1994b:140) y más adelante junto a Gregory Batenson filmó diez horas en Bali y Nueva Guinea de 1936 a 1938.

Ya en Adolescencia y cultura reflexionaba sobre futuros trabajos de campo. "[Sobre su primer trabajo de campo] Se trata de estudios de iniciación, hechos con un método que no volveré a emplear. Mi labor futura (...) se realizará en colaboración, e intervendrán por lo menos dos y aún hasta seis observadores provistos de modernos métodos de documentación acompañados por mecanógrafos o taquígrafos, cámaras en miniatura y filmadoras (...). Los resultados de estos modernos métodos serán más valiosos que los estudios primitivos, y proporcionarán mucho más detalles que luego podrán ser utilizados" (1928:13). Su idea consistía en utilizar el material recabado sólo como de registro.

Otros antropólogos estuvieron interesados en el uso de lo visual dentro de la antropología, uno de ellos fue Franz Boas, "quien hasta 1930, a la edad de 70 años, filmó una serie de danzas kwakiutl” (Henley, 2001:19). 


\section{Dialogar con luz: etnografía colaborativa a partir de la fotografía}

Cuando Urteaga pone en el centro de la discusión visibilizar a las juventudes indígenas y a las juventudes migrantes en los estudios recientes, es también vigente traer a la luz de todos, la importancia de estudiar la vida amorosa y sexual de las juventudes a partir de la antropología; en ésta:

el giro hermenéutico ha permitido el retorno al sujeto, el reconocimiento del punto de vista del "nativo" y la interdiscursividad en la construcción del conocimiento antropológico al des-centrar la mirada al objeto, la discusión sobre la diversidad, la identidad, la subjetividad, etcétera, y una preocupación por elaborar nuevas metodologías para estudiar a los sujetos que construyen la contemporaneidad (2011b:15).

Es necesario buscar otras formas distintas de trabajar. La propuesta es elaborar etnografías que den cuenta de los significados que tienen el amor y la sexualidad para los jóvenes contemporáneos. Las imágenes pueden ser sin duda un buen camino;

resulta incuestionable la importancia que puede tener la imagen para la antropología en tanto instrumento para la investigación etnográfica. (...) la imagen describe, encierra y transmite información, ideas y significados. Las fotos y los videos pueden servir como recordatorio, como auxiliares de la memoria y detonadores de ideas y reflexiones para el investigador. Las imágenes y la cultura visual representan una fuente inagotable de investigación, constituyen una alternativa legítima para comunicar experiencias etnográficas y generar nuevas formas de conocimiento antropológico (Zirión, 2015:51).

Es necesario que utilicemos estrategias que ayuden a crear un conocimiento donde intervengan los interlocutores y no sólo el antropólogo o el etnógrafo como solían producirse las etnografías ya clásicas en la disciplina. Es necesario modificar preceptos originales de la antropología en la cual el antropólogo observaba y hablaba como el "auténtico y válido conocedor" de un grupo cultural.

Estas estrategias ya han sido utilizadas desde la antropología visual, específicamente a través de la realización de documentales, estoy hablando de estrategias colaborativas en las que el diálogo intercultural es principio básico (Zirión, 2015). Se trata de una propuesta pretérita que no ha sido tan difundida como otras pero que hoy más que nunca tiene grandes posibilidades.

En el texto citado, Zirión hace referencia al cine etnográfico y al documental colaborativo. Para efectos de este trabajo se propone trabajar a partir de la fotografía colaborativa; de lo que se 
trata es que interlocutores e investigadores observen, participen, escuchen y entablen un diálogo. Se busca que todas las partes se involucren, intervengan y cooperen.

La etnografía colaborativa es una propuesta trabajada en otros países de América Latina, por ejemplo, Katzer y Samprón en Argentina la proponen como una perspectiva analítica. Katzert trabajó con indígenas qom que habitan en la Provincia de Buenos Aires y Samprón con indígenas huarpes de la Provincia de Mendoza. Al desarrollar sus tesis doctorales decidieron intercambiar experiencias etnográficas basándose en sus notas de campo y en sus registros fotográficos elaborados entre 2005 y 2010.

Retomando a George Marcus los autores definen la etnografía como "un estilo narrativo de producción de conocimiento que se configura procesualmente" donde la clásica relación que se establece durante la investigación etnográfica pasa al ámbito de lo colaborativo. Ahora se comparten en los textos las narrativas sobre el encuentro etnográfico y sobre el resto del trabajo de campo.

Es la necesidad de problematizar las diversas modalidades de contacto entre los etnógrafos y los interlocutores, de analizar las complejidades y ambigüedades del proceso de lectura y escritura etnográfica, la noción de colaboración ha ido adquiriendo relevancia teórica, al punto de convertirse en un enfoque metodológico preciso. Entendiendo el vínculo etnográfico como colaborativo, el "informante" pasa a ser concebido como consultor, co-teorizador y socio epistémico, reconociendo en dichas categorizaciones, la agentividad de su labor conceptual, de interpretación e incluso, de escritura (Katzer y Samprón, 2011:61).

De esta manera se reconoce que los sujetos investigados pasan a formar parte de un proceso de investigación en el que intervine todo el tiempo y en el que se hace presente un compromiso por parte del etnógrafo de colaboración con los sujetos de estudio. Existe un intercambio de informaciones y se crea una especie de código que consiste en:

responsabilidad respecto de los consultores con los cuales se trabaja como preocupación primaria; establecimiento de un vínculo con la comunidad de estudio que posibilite la continuidad y que no se reduzca a un mero medio para la construcción de la obra; acceso a las entrevistas y productos del estudio por parte de todos los participantes del proyecto; comunicación de intenciones, planes y metas del proyecto; apertura a las experiencias y perspectivas de los "consultores", aun cuando difieran; responsabilidad hacia la comunidad en estudio, academia y disciplina para la finalización de la publicación etnográfica (2011:66).

Bajo esta lógica en la práctica la etnografía es reflexiva, el diálogo intercultural se hace presente pues tanto el etnógrafo como los interlocutores trabajan a la par; son tomadas en cuenta las 
experiencias de todos los que intervienen, se trata de tomar en cuenta las experiencias del investigador y las de los interlocutores, sólo así se logrará construir un conocimiento que se acerque lo más posible a la realidad, para esto es indispensable tomar una perspectiva en la cual la etnografía contemple la lectura, edición, co-interpretación compartida además de una acción colaborativa. Esta perspectiva nos abrirá la posibilidad de que los interlocutores guíen al investigador en situaciones, prácticas y narrativas que por nuestra propia cuenta no podríamos tomar como relevantes. Esta manera de trabajar la etnografía, "nos permite elaborar las divergencias, las tensiones, con los sujetos con los que trabajamos" (2011:66).

Samprón escribe en su diario de campo que cuando terminó uno de los talleres de memorias que trabajaba con jóvenes, algunos se acercaron para pedirle que los ayudará a realizar un video clip, esto lo hizo replantear y renegociar la propuesta "Creo que es más interesante trabajar sobre sus propias propuestas, en sus propios territorios simbólicos, reconocer su agencia, su poder, y el poder transformador de sus palabras, y su música” (2011:66). Al trabajar con los jóvenes indígenas qom urbanos a partir de la etnografía colaborativa Sampróm reporta que eso les permitió poner atención en lugares que sólo los jóvenes pudieron identificar como claves, difícilmente los antropólogos o los interlocutores secundarios habrían llegado a la conclusión de asistir a ellos. Como enuncia Zirión, se necesita observar, participar, escuchar y ser escuchado para llegar al diálogo, al diálogo intercultural que necesita la antropología de hoy día.

Otro trabajo que ayuda a ejemplificar la propuesta es el de tres académicas argentinas. Graciela Batallán, Liliana Dente y Lorely Ritta presentaron la ponencia titulada "Taller de investigación con producción audiovisual como instancia coparticipante de indagación etnográfica". En esta ponencia expusieron los resultados del desarrollo de un taller de investigación y producción audiovisual en el que participaron adolescentes de un barrio en pobreza extrema en la Ciudad Autónoma de Buenos Aires. Su objetivo es fundamentar la validez de la información obtenida por ser por un lado, fuente primaria, y por el otro, por haberse generado en una instancia coparticipante como lo fue el taller, aun cuando su encuadre quebrante los parámetros objetivistas del canon del trabajo de campo. Para las académicas este tipo de metodología cuestiona la posición en que se encuentra el sujeto que investiga y el objeto investigado en dicho proceso:

Es necesario profundizar críticamente en los criterios de validez y legitimidad de la información de campo inscritos en la clásica Observación Participante de la antropología, cuestionando no sólo el 
lugar predominante que en general se le atribuye a la observación del investigador como garante de la "objetividad", sino también el lugar inocuo asignado a la noción de participación, asociada a la presencia física del investigador en el campo (2014:3).

La propuesta de las autoras va encaminada a cuestionar la asimetría entre investigador y los actores. Su noción de participación se sustenta en la reciprocidad de perspectivas, "es decir, en el desarrollo de un diálogo (o coparticipación) que busca la comprensión del lenguaje y de los códigos de los hablantes" (2014:4). La coparticipación permite considerar los registros como auténticos pues lo agentes comprenden la lógica de su investigación y su lenguaje. De esta manera se abre la posibilidad de que los protagonistas aporten en la construcción del conocimiento al igual que cuestionen el análisis del investigador.

Batallán, Dente y Ritta proponen el uso de la herramienta audiovisual con el objetivo de entender la prácticas y el pensamiento político de los adolescentes; consideran que la metodología del taller les permitiría a los participantes desplegar sus reflexiones respecto a los temas. Su hipótesis es que los intereses sociales y políticos de los adolescentes son desconocidos, ignorados e invisibilizados por los adultos.

El intercambio conversacional dirigido a fortalecer el interés de los jóvenes para investigar y comprometerse con el desafío de sostener la participación, la ausencia de evaluación y puntajes, y la búsqueda de espacios subjetivos de placer en relación con la actividad intelectual también modifican radicalmente las modalidades de vinculación entre jóvenes y adultos, y consiguen desplazar el temor y la resistencia inicial (2014:7).

La propuesta de las autoras para estudiar las prácticas y el pensamiento político es en gran parte igual a mi propuesta de trabajar bajo la modalidad de talleres, en los que a través de las fotografías de los propios jóvenes sobre su vida cotidiana, sobre la convivencia que tienen con los amigos, la familia, los compañeros de la escuela o el trabajo, así como con la pareja y en soledad logren crear narrativas visuales que aporten expresar y transmitir su condición. A través de la creación de fotografías se busca que los jóvenes se desinhiban al tratar temas que se encuentran en el campo de lo privado y lo íntimo; la idea es motivar a los participantes a que expresen opiniones que ayuden a construir saberes juveniles.

Aun cuando la fotografía no sea una imagen fiel de la realidad no deja de reflejar comportamientos y gestos con fuerte significado social. Fija rituales de interacción que (...) son particulares (...) de la sociedad en su conjunto. (...) En la imagen fotográfica encontramos estereotipos, signos de estatus social, relaciones de poder y formas sociales que son familiares a los miembros de la misma 
cultura. (...) La fotografía como técnica que permite entender el pensamiento, las prácticas y experiencias de distintos grupos sociales, puede usarse como evocadora de imaginarios, representaciones, o como ayuda para construir la memoria. En el desarrollo de entrevistas individuales o grupales, la fotografía ha mostrado su eficacia como generadora de narrativas y discursos en torno a temas asociados a las imágenes (Alba, 2010:51-56).

\section{La discusión continúa}

En este ensayo he esbozado las primeras ideas teóricas y metodológicas que busco desarrollar a lo largo del próximo año. Sin lugar a duda será hasta que se ponga en práctica la propuesta que podremos saber si la imagen, captada por una cámara fotográfica (o la cámara de un celular), puede ayudar a adentrarnos en este tema tan importante y tan ausente de las investigaciones sobre la población joven del país.

Considero que la fotografía es imagen, palabra y objeto a la vez, a través de ella los jóvenes tendrán la oportunidad de plasmar lo que les interesa, lo que los define, lo que les brinda identidad.

Es pertinente aclarar que la fotografía colaborativa está siendo trabajada también a través de las redes sociales, "La fotografía colaborativa, social, interactiva y participativa se instaura en el mundo actual de mano de los celulares con cámara conectados a Internet y las redes sociales" (Bañuelos, 2014). Actualmente existen aplicaciones (apps) en el que los usuarios sin conocerse pueden crear series fotográficas. Se trata de aplicaciones en las que cualquiera participa como colaborador público o privado (dos ejemplos son Pixplit y Dubble).

Para llegar a esta propuesta me fue necesario conocer los trabajos más sobresalientes que sobre jóvenes se han llevado a cabo en los últimos quince años, es decir, desde el inicio del nuevo siglo. Como se vio, la antropología se ha abierto al estudio de diferentes sociedades sin importar que se encuentren en territorios definidos y con poca comunicación o que habiten en grandes ciudades, como lo es la capital del país, donde la interculturalidad es el pan de cada día. La propuesta es que chicos y chicas, a través de la fotografía, generen narrativas sobre los significados de las prácticas y los imaginarios que respecto al amor y a la sexualidad tienen.

Por otro lado, es de mi particular interés remarcar que ninguno de los estudios con trabajo empírico sobre la vida amorosa y sexual de las personas jóvenes fue realizado en la Ciudad de México. Esto en definitiva es un reflejo de los pendientes que aún tenemos en la agenda por resolver. La invitación a la discusión está abierta. La fotografía del amor y la sexualidad entre 
jóvenes en el México actual no es estática, jóvenes y no jóvenes participamos es su reconfiguración y la antropología mucho puede ayudarnos a comprender estos temas tan íntimamente relacionados con la subjetividad de las sociedades en el siglo XXI. 


\section{Referencias bibliográficas}

Alba González, Martha de (2010), "La imagen como método en la construcción de significados sociales" en Iztapalapa. Revista de Ciencias Sociales y Humanidades. Nueva época, año 31, número 69, julio-diciembre, México: UAM, pp.41-65

Bañuelos, Jacob (2011), "Fotografía colaborativa y ciudadanía" en 24 horas. El diario sin límites, 4 de noviembre. Recuperado en www.24-horas.mx/fotografía-colaborativa-y-ciudadanía

Batallán, Graciela, Dente, Liliana y Lorely Ritta (2014), "Taller de investigación con producción audiovisual como instancia coparticipante de indagación etnográfica". Ponencia presentada en el V Congreso Argentino de Antropología Social, Argentina: Universidad Nacional de Rosario Argentina, julio, pp.1-21

Bateson, Mary Catherine (2004) [1984], Como yo los veía. Margaret Mead y Gregory Bateson recordados por su hija. Traducción de Daniel Zadunaisky, Barcelona: Gedisa.

Brito Lemus, Roberto (2000), "Elementos para contextualizar la juventud" en La juventud en la Ciudad de México: políticas, programas, retos y perspectivas. México: Dirección de Programas para la Juventud-GDF, pp. 7-16

Calderón Rivera, Edith (2012), La afectividad en antropología. Una estructura ausente. Prólogo de Catherine Lutz, México: CIESAS-Casa Chata/UAM

CEPAL, Invertir para transformar. La juventud como protagonista del desarrollo (2014) México: CEPAL/OIJ/IMJUVE Recuperado en www.oij.org/es_ES/publicacion/invertirpara-transformar

Collignon Goribar, María Martha (2003), "Tejidos sobre la sexualidad juvenil” en Revista Electrónica Sinéctica. Número 23, agosto-enero, Jalisco: ITESO, pp.43-50

Collignon Goribar, María Martha y Rodríguez Morales, Zeyda (2010), “Afectividad y sexualidad entre los jóvenes. Tres escenarios para la experiencia íntima en el siglo XX" en Reguillo, Rossana (coord.), Los jóvenes en México, colección Biblioteca Mexicana, serie Historia y Antropología, México: FCE/CONACULTA, pp.262-315

CONAPO (2010), La situación actual de los jóvenes en México. Serie de documentos técnicos, México: CONAPO

CONAPRED (2011), Encuesta Nacional sobre Discriminación en México (ENADIS 2010). Resultados sobre las y los jóvenes. México: CONAPRED/IMJUVE

Corona Berkin, Sarah y Rodríguez Morales, Zeyda (2000), "El amor como vínculo social, discurso e historia: aproximaciones bibliográficas" en Espiral. Estudios sobre Estado y Sociedad. Volumen 6, número 17, abril, Guadalajara: Universidad de Guadalajara, pp. $49-70$

Díaz Sánchez, Josefina (2006), "Identidad, adolescencia y cultura. Jóvenes secundarios en un contexto regional" en Revista Mexicana de Investigación Educativa. Año 11, volumen 11, número 29, abril-junio, México: Consejo Mexicano de Investigación Educativa A.C., pp. 431-457.

Esteinou, Rosario (2005), "La juventud y los jóvenes como construcción social” en Mier y Terán, Martha y Rabell, Cecilia (coords.), Jóvenes y niños. Un enfoque sociodemográfico. 
México: Cámara de Diputados LIX Legislatura/ISS-UNAM/FLACSO México/Miguel Ángel Porrúa, pp.25-37

Frazer, James G. "Prefacio" (2001) [1922], Los argonautas del Pacífico occidental. Comercio y aventura entre los indígenas de la Nueva Guinea melanésica. Prefacio de James G. Frazer, traducción de Antonio J. Desmonts, Barcelona: Ediciones Península, pp.15-25

García Canclini, Néstor (2005), Diferentes, desiguales y desconectados. Mapas de la interculturalidad, Barcelona: Gedisa

(2012), "Introducción. De la cultura postindustrial a las estrategias de los jóvenes" en García Canclini, Néstor, Cruces, Francisco y Maritza Urteaga Castro Pozo (coords.), Jóvenes, culturas urbanas y redes digitales. Prácticas emergentes en las artes, las editoriales y la música, Madrid: Ariel/UAM/Telefónica, pp.3-24

González, Susana, "Pobres, 45\% de jóvenes mexicanos, pero gobiernos recortan apoyos" en Periódico La Jornada, sección Economía, Lunes 24 de noviembre de 2014. Recuperado en www.jornada.unam.mx/2014/11/24/economia/024n1eco

Henley, Paul (2001), "Cine etnográfico: tecnología, práctica y teoría antropológica” en Desacatos. Revista de Antropología Social. Lo visual en antropología. Número 8, invierno, México: CIESAS, pp.17-36

Ilizarde, Carmen (1999), "Todavía no somos quienes queremos ser. Construcciones sociales del amor y la pareja en jóvenes de sectores medios de Lima" en Panfichi, A., y Varcárcel, M. (eds.), Juventud, Sociedad y Cultura. Lima: Red para el Desarrollo de las Ciencias Sociales en el Perú, pp. 471-505

IMJUVE (2011), Encuesta Nacional de Juventud 2010. Resultados generales. México: IMJUVE

IMJUVE (2012), Encuesta Nacional de Valores en Juventud 2012. Serie Doctrins Jurídica, número 653, México: IIJ-UNAM/IMJUVE

INEGI, Censo de Población y Vivienda 2010, México

Katzer, Leticia y Samprón, Agustín (2011), “El trabajo de campo como proceso. La 'etnografía colaborativa' como perspectiva analítica" en Revista Latinoamericana de Metodología de la Investigación Social. Año 1, número 2, octubre-marzo, pp.59-70

Ley de las y las jóvenes del Distrito Federal (2000) en Gaceta Oficial del Distrito Federal, 25 de julio. Recuperado en www.jovenes.df.gob.mx/transparencia1013/fraccion_I_art_14/5.pdf

Lyons, Andrew P. y Lyons, Harriet D. (2006), "The New Anthropology of Sexuality" en Anthropological. Volumen 48, número 2, Canadá: Canadian Anthropology Society pp.153-157. Recuperado de www.jstore.org/stable/25605307

Malinowski, Bronislaw (2001) [1922], Los argonautas del Pacífico occidental. Comercio y aventura entre los indígenas de la Nueva Guinea melanésica. Prefacio de James G. Frazer, traducción de Antonio J. Desmonts, Barcelona: Ediciones Península (1961) [1927], Sex and Repression in Savage Society. London: Routledge (1975) [1929], La vida sexual de los salvajes del Noroeste de la Melanesia. Prólogo del Dr. Gregorio Marañón, Madrid: Ediciones Morata 
Mead, Margaret (1995) [1928], Adolescencia y cultura en Samoa. Prefacio de Franz Boas, traducción de Elena Durkelsky Yoffe, Barcelona: Paidós Studio

(1976) [1930], Growin Up in New Guinea: A Comparative Study of Primitive Education. Estados Unidos: William Morrow \& Company

(1994a) [1935], Sexo y temperamento en tres sociedades primitivas. Traducción de Inés Malinow, Barcelona: Paidós Studio/Básica

(1994b) [1972], Experiencias personales y científicas de una antropóloga. Traducción de Claudia S. Seibert de Yujnovsky, Barcelona: Paidós Básica

Mendoza Enríquez, Hipólito (2011), "Los estudios sobre la juventud en México" en Espiral. Estudios sobre Estado y Sociedad. Volumen 18, número 52, septiembre-diciembre, Guadalajara: Universidad de Guadalajara, pp.193-224

Morduchowics, Roxana (2008), La generación multimedia. Significados, consumos y prácticas culturales de los jóvenes. Voces de la educación, Buenos Aires: Paidós

Murdock, George Peter (1943), "Bronislaw Malinowski" en American Anthropologist, nueva serie, volumen 45, número 3, parte 1, julio-septiembre, Estados Unidos: Wiley/American Anthropological Asociation, pp.441-451. Recuperado de www.jstore.org/stable/663181

Otero, Analia E. (2010), "Los avatares de la transición a la vida adulta, el papel de la educación y el trabajo en los recorridos juveniles" en Margen59. Revista de Trabajo Social y Ciencias Sociales. Edición 59, primavera, Buenos Aires: Revista Margen de edición digital, pp.1-13

Patiño Torres David (2012), "INEGI revela datos sobre los jóvenes mexicanos" en Periódico Sexenio, sección Nacional, 9 de agosto de 2012. Recuperado en www.sexenio.com.mx/articulo.php?id=18172

Ramírez Herrera, Ana María (2003), "Honor, moral y sexualidad en la cultura purhépecha: reglas y normas de comportamiento en las relaciones de pareja”, en Seefoó Luján, J. Luis y Ramírez Sevilla, Luis (eds.), Estudios Michoacano XI, Colección Estudios, Zamora: El Colegio de Michoacán, pp. 53-73.

Reguillo, Rossana (2006), "Prólogo. El amor en tiempos de transición” en Rodríguez Morales, Zeyda, Paradojas del amor romántico. Relaciones amorosas entre jóvenes. Prólogo de Rossana Reguillo, Colección Jóvenes, número 18, México: IMJUVE, pp.13-16

(2012a), Culturas juveniles. Formas políticas del desencanto, Colección Mínima, Buenos Aires: Siglo XXI

(2012b), "La condición juvenil en el México contemporáneo. Biografías, incertidumbres y lugares" en Reguillo, Rossana (coord.), Los jóvenes en México. Colección Biblioteca Mexicana, México: FCE/Conaculta, pp.395-429

Rodríguez Morales, Zeyda (2006), Paradojas del amor romántico. Relaciones amorosas entre jóvenes. Prólogo de Rossana Reguillo, Colección Jóvenes, número 18, México, Instituto Mexicano de la Juventud 
Rodríguez Ramírez, Gabriela y De Keijzer, Benno (2002), La noche se hizo para los hombres. Sexualidad en los procesos de cortejo entre jóvenes campesinas y campesinos. Presentación de Soledad González Montes, México: Population Council-EDAMEX

Toñón, Esperanza, Ayús Ramfis y Luis Alberto Montejo (2004), "La sexualidad, un campo de significados. Fuentes de información y educación sexual entre jóvenes de Tabasco" en Rossana, Reguillo, Feixa Carles y José Antonio Pérez Islas et al. (coords.), Tiempo de híbridos. Entresiglos jóvenes México-Cataluña, Colección Jóvenes, número 14, México: IMJUVE, pp. 55-69

Tourliere, Mathieu (2014), "Más de 50\% de jóvenes mexicanos vive en la pobreza: Cepal” en Revista Proceso digital, 19 de noviembre, México. Recuperado en www.proceso.com.mx/?p=388275

Urteaga Castro Pozo, Maritza (2011a), La construcción juvenil de la realidad. Jóvenes mexicanos contemporáneos. Biblioteca de Alteridades 18, México: UAM/Juan Pablos Editor (2011b), "Retos contemporáneos en los estudios sobre juventud" en Alteridades. Jóvenes en América Latina. Abordajes desde la antropología. Año 21, número 42, juliodiciembre, México: UAM, pp. 13-32

Urteaga, Maritza y Sáenz Ramírez, Mauricio (2012), “Juventudes, géneros y sexos. Resituando categorías" en Revista del Centro de Investigación. Volumen 10, número 3, enero-julio, Distrito Federal: Universidad La Salle, pp. 5-21

Valenzuela Arce, José Manuel (2002), “Jóvenes y juventudes en México” en Pérez Islas, José Antonio, Jóvenes mexicanos del siglo XXI. Encuesta Nacional de Juventud 2000, México: IMJUVE, pp.26-51

Zirión Pérez, Antonio (2015), "Miradas cómplices: cine etnográfico, estrategias colaborativas y antropología visual aplicada" en Iztapalapa. Revista de Ciencias Sociales y Humanidades. Nueva época, año 36, número 78, enero-junio, México: UAM, pp.45-70 


\section{$A 17$ possereaco \\ Casa abierta al tempo 7 ANTROPOLÓGICAS}

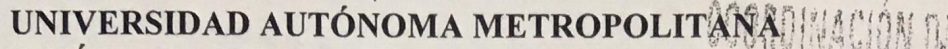

DIVISIÓN DE CIENCIAS SOCIALES Y HUMANIDADES

DEPARTAMENTO DE ANTROPOLOGÍA

CONSTANCIA DE EVALUACIÓN DEL ENSAYO

PARA LA OBTENCIÓN DEL DIPLOMA EN LA

ESPECIALIZACIÓN EN ANTROPOLOGÍA DE LA CULTURA

\begin{tabular}{|c|c|c|}
\hline DIA & MES & AÑo \\
17 & 07 & 2015 \\
\hline
\end{tabular}

ALUMNA: MONTOYA GASTELÚM GABRIELA

MATRICULA: $\underline{2143800179}$

TRIMESTRE 15-P

DIRECTOR: DR. NÉSTOR RAÚL GARCÍA CANCLINI

LA ALUMNA PRESENTÓ EL ENSAYO TITULADO:

FOTOGRAFÍA DEL AMOR Y LA SEXUALIDAD ENTRE JÓVENES EN EL MÉXICO ACTUAL.

OBTENIENDO LA CALIFICACIÓN DE:

APROBAR $\Varangle)$

DIRECTOR DEL ENSAYO

DR. NÉSTOR BAOL GARCÍA CANCLINI

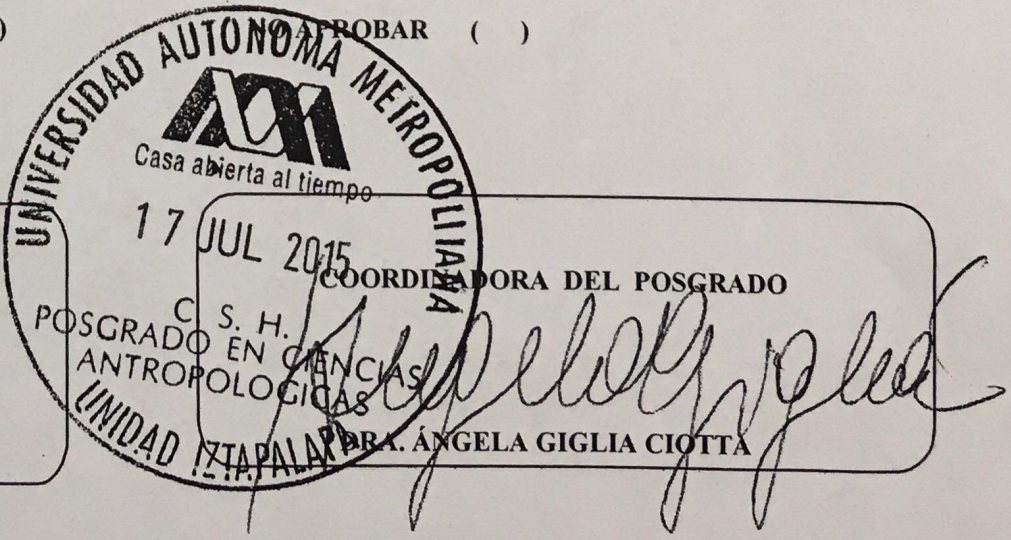

